\title{
Contexto histórico e reflexões sobre hipertextos, hipermídia e sua influência na cultura e no ensino do Século XXI
}

\section{Resumo}

Maria Isabel Timm ${ }^{l}$

Fermando Schnaid ${ }^{2}$

Milton Antônio Zaro ${ }^{3}$

$\mathrm{O}$ artigo apresenta e reflete sobre elementos relacionados à contextualização histórica das estruturas hipertextuais de produção, acesso e recuperação de informações, com base em rápidos resumos das idéias de Vannevar Bush e Ted Nelson, considerados precursores de sua implementação, bem como da contribuição de Doug Engelbart com o desenvolvimento de periféricos - o mouse e o teclado - que viabilizaram a agilidade da interação homem-computador e, portanto, contribuíram para a instantaneidade, uma desejada característica dos hipertextos mediados por esta tecnologia. Estabelece algumas reflexões relacionadas às naturezas da hipermídia, enquanto meio de comunicação social, uma das quais a natureza técnica, puramente informacional, e outra criativa, estética, quase artística, que permite ao planejador incluir a sensorialidade e a emoção aos recursos narrativos e à representação de conteúdos. Reflete sobre a inserção desse tipo de

comunicação na cultura contemporânea, alterando as possibilidades de percepção e representação da realidade e, em função disso, do ensino, em especial do ensino a distância, cuja história e desenvolvimento ficou definitivamente marcado pela mediação tecnológica dos computadores e da Internet, com sua linguagem marcadamente hipertextual.

\begin{abstract}
This work presents and reflects about hypertext historical context, based on Vannevar Bush and Ted Nelson ideas - both of them being considered the fathers of hypertext structure -, as well as Doug Englebart contribution to the real possibility of using them, by developing the mouse and windows technology. It also reflects about hypermedia nature, both technical and creative, almost artistic, enabling the use of emotion and sensorial effects, to improve general narrative possibilities. Finally, it focuses on how hypermedia can interfere with perception and representation patterns in contemporary culture, and its influence over distance education based on computers and Internet.
\end{abstract}

\section{Não-linearidade, interatividade, instantaneidade, informação e arte}

A forma de produção de informações através da união entre um termo, por exemplo, e seu significado, não surge no século XX, com os hipertextos computadorizados. Na verdade, pode-se pensar nas indicações de verbetes de enciclopédias (a conhecida expressão ver também...) como possibilidades de

1 Jornalista; Doutoranda do PGIE/UFRGS; coordenadora do Núcleo de Multimídia e Ensino a Distância NMEAD/Grupo de Educação Tecnológica da Escola de Engenharia-GET/UFRGS (betatimm@ufrgs.br)

$2 \mathrm{PhD}$, Oxford, UK. Professor Escola de Engenharia da UFRGS; coordenador NMEAD/GET/UFRGS (fernando@ufrgs.br)

${ }^{3}$ Dr., Professor Escola de Engenharia da UFRGS; coordenador NMEAD/GET/UFRGS (zaro@ufrgs.br) 
realizar ligações e sentidos, capazes de conduzir o leitor a uma busca de maiores informações sobre um tema, e mesmo à sua própria decisão sobre prosseguir ou não com aquela busca. $\mathrm{O}$ mesmo acontece com o leitor que recorre às notas de rodapé existentes em seu livro. Estaria, desta forma, exercendo o que vem sendo considerado como algumas das características principais dos hipertextos que servem, hoje, para estruturar as informações na Internet, ou em alguns produtos que usam hipermídia: a não-linearidade e a interatividade. Embora as duas formas citadas - relação entre verbetes e acesso a notas de rodapé - contenham na sua concepção o acesso à não-linearidade do conteúdo e o apelo à interação do leitor, será através dos chamados hipertextos atuais, mediados pelo computador, que ambas as características vão cumprir com o que realmente prometem à mente curiosa e operativa dos humanos, ao se associar à instantaneidade, à magia do acesso ao conteúdo conectado a um simples apertar de botão, ou a um simples clique de mouse, como este ato ficou conhecido no jargão da cultura contemporânea, completamente marcada pela comunicação virtual.

Nesse tipo de linguagem hipertextual, um link pode levar instantaneamente - não apenas a outra informação (texto, imagem, etc.), mas a um outro rumo que poderá determinar a continuidade ou não do raciocínio iniciado, ou, o que acontece com frequência, instigar a curiosidade do navegador por informações diferentes daquelas que mobilizaram sua busca inicial. Caberá ao usuário desse trabalho - e não apenas ao seu autor - a responsabilidade pela construção de outras conexões e, em função disso, outras leituras, outros nexos, além daqueles que foram pensados e propostos pelo organizador da informação, isso sem cogitar-se no acaso (às vezes também planejado) das conexões criadas por softwares de busca em redes internas e na própria Internet. Os hipertextos computadorizados, enquanto estruturas não-lineares e interativas, as quais permitem

uma construção de redes de conexões e sentidos, passaram à história da comunicação e da educação na segunda metade do Século XX, popularizando-se seu estudo e sua inserção na última década do mesmo Século.

A operação individual do computador pessoal (PC), por si só, acarretou uma necessidade de compreensão de nova forma hipertextual de documentar, acessar a informação, representar o mundo, comunicar idéias e conteúdos e, portanto, mediar o processo educacional. Hillis (2000) tem uma forma peculiar de pensar sobre a comunicação mediada pelo computador, propondo aos planejadores de seu uso para fins de comunicação (e, portanto, de educação), o exercício pouco usual de acrescentar uma nova dimensão - o tempo - à equação dos projetos de forma e conteúdo de suas mensagens.

Comunicar, diz o autor, é um ato de oferta de uma mensagem a alguém, através de um determinado espaço. Documentar, pelo mesmo raciocínio, seria o mesmo ato - ofertar uma mensagem - a alguém (ou à própria pessoa que documentou) a uma outra época, portanto, a um outro tempo. O PC é capaz de integrar essas possibilidades de forma notável, diz o autor, potencializando a faculdade humana da memória, com sua múltipla capacidade de representação em linguagens diversas. Através dele, e das suas características atuais, que incluem a portabilidade, tornou-se possível possível viajar no tempo e no espaço (mantendose a metáfora do autor) e acessar, com um clique, o produto da documentaçãoseja ele uma informação ou uma obra de arte, em qualquer tempo e em qualquer espaço. Esse produto, graças à mediação tecnológica, torna-se presente em formatos cada vez mais variados, em arquivos de texto, som e imagem cada vez 
mais diversificados e fiéis à representação inicial, não apenas na sua significação primitiva, mas integrado a um conjunto hipertextual e dinâmicos de sentidos onde forma, conteúdo, sintaxes e elementos variados compõem uma linguagem nova, hipermidiática, ainda inexplorada em todas as suas potencialidades.

O computador pessoal também estendeu a capacidade e viabilizou o desejo humano de interagir, de intercambiar documentação, de comunicar conhecimentos e, pela vida da mídia em que se transformou, comunicar sensações e sentimentos. Os meios de comunicação social - sejam eles a pintura rupestre ou um audiovisual editado eletronicamente - contêm, em si, a natureza simultânea da técnica e da arte, da informação e da sensibilização de sentidos e emoções.

Um filme não apenas informa os dados antropológicos, a codificação dos costumes de uma determinada cultura, mas emociona os que o assistem, tanto quanto um tele-jornal, que documenta o fato cotidiano através da imagem tecnicamente composta, da linguagem clara e precisa e de uma sinergia entre elas e, talvez, uma trilha sonora, ou mesmo uma entonação de voz do locutor ou repórter, que vai transmitir a emoção por trás do fato. Uma boa idéia para se pensar sobre essa possibilidade é lembrar daqueles que são considerados bons repórteres - na mídia escrita ou audiovisual - de cujos textos pode se depreender a cor, o som, o cheiro e as demais informações da vida real contida no fato noticiado. Esta é a natureza arte, associada à natureza informação, contidas ambas nos meios de comunicação, ou mídias, ou nas tecnologias da inteligência, segundo expressão cunhada por Pierre Levy (1993), todas as quais têm em comum, segundo o autor, o poder de, mesmo tendo sido criadas pelo homem, moldar sua mente, moldando-lhe a forma de pensar e estruturar a comunicação. Essas naturezas, em permanente sinergia e interconectadas pelas redes de sentidos hipertextuais (portanto, hipermidiáticas), são acessíveis hoje também através dos PCs e suas potencialidades são acessíveis (mesmo que não em nível universal) a qualquer tempo/espaço em que se instale um computador, em especial se estiver conectado à Internet, o que faz desses dois personagens do Século XX - mídia e computador - interfaces indissociáveis, criador e criatura, recíprocos e biunívocos, aliados entre si e à disposição de quem puder e souber usá-los eficientemente para todos os fins, em especial para fins educacionais.

A ser confirmada essa suposta natureza simbiótica com a mídia, o computador pessoal terá conseguido algumas grandes proezas relacionadas à configuração dos padrões cognitivos humanos de reconhecimento e interpretação de informações: re-agendar a percepção humana sobre os formatos de sua própria capacidade de documentação e comunicação, agregando-lhe (ou conscientizandolhe a respeito de)

um novo e complexo sentido, o sentido hipermidiático, integrador de múltiplos estímulos à sensorialidade. Se assim for, pode-se dizer que sincronizam-se no mundo da representação virtual, por exemplo, as várias nuances e possibilidades de todo tipo de som, reais ou inventados, como trilha, ruído ou locução; imagens de múltiplos tamanhos, proporções e noções de espacialidade re-inventadas, em composições que desafiam os padrões convencionais que se referem à atenção e à capacidade de percepção do navegador, construindo na tela o que não existe no mundo real. A esses dois elementos historicamente tão íntimos que consagraram uma palavra para designá-los - o áudiovisual - integraram-se movimentos multidirecionais, que transformam e trans-morfam imagens, umas em outras, criando novas imagens ou novos conceitos, verossímeis ou não, representativos ou não, estéticos ou não... 
A esse re-agendamento da percepção de representação de som, imagem e movimento, trazido ao computador pela sua natureza mídia, soma-se a instantaneidade possibilitada pela nova tecnologia e, portanto, desejada pelo produtor e pelo usuário. Nas duas pontas da interação com a hipermídia - a produção e o uso - espera-se não menos do que uma resposta instantânea a qualquer clique, uma máquina tão eficiente quanto o desejo ou o pensamento. Um desejo ainda distante da realidade dos processadores, das interfaces e dos acessos às redes atuais, mas um desejo, que por certo estabelece uma expectativa cognitiva em relação aos prazos para a evocação de significados a partir de estímulos tão intensos e multifacetados. Deseja-se a instantaneidade e, com ela, o usufruto da nova forma associativa de cognição e de produção, ambas possivelmente fragmentadas e, com certeza, hipertextuais.

Liberados da obrigatoriedade do modelo linear que contém início-meiofim, consolidado pelo livro (ver Levy, 1993, sobre a linearidade da escrita), os usuários dos computadores podem nem saber exatamente o que é um hipertexto (estruturas de informação formadas por blocos integrados por elos, ou links), mas já usufruem do clique aqui com a naturalidade das ações culturais cotidianas, como ligar a televisão e trocar de canal. Talvez nem mesmo pensem em hipermídia quando acionam um vídeo, nos web-sites de jornalismo, nem conscientizem que as salas de bate-papo (chat) sejam ferramentas de compartilhamento de informações, cujo potencial educativo excita o mundo da pesquisa das novas tecnologias educacionais. Mesmo sem pensar, os usuários dos computadores e da rede provavelmente muito em breve terão também aprendido inconscientemente -, nestas salas de chat, mais um novo tempo/espaço/comportamento, desta vez não instantâneo, mas ao contrário, mais lento, que contém um novo jeito de se comunicar, num ritmo que inclui digitação, envio das mensagens, atualização das janelas de chat, quedas eventuais do sistema, abreviaturas e ícones expressivos (emoticons) e, se houver muitas pessoas conectadas na sessão, uma mistura nem sempre organizada de assuntos aos quais atentar e responder, numa nova interatividade multiplicada por múltiplas atenções, da qual, talvez, se possa dizer que se trata do mesmo novo sentido hipertextual, acionado agora na forma de interação.

Isso posto, possivelmente o leitor já nem lembre do seu próprio pensamento sobre os seus documentos, suas idéias e sobre o mundo da informação e da comunicação antes de que interagisse com eles o onipresente computador, como possivelmente não identifique tampouco, como seria seu pensamento se não conhecesse o rádio, a televisão ou cinema (ou as suas linguagens, agora integradas no computador). Dificilmente poderá, sem estímulo, excluir de sua própria percepção de som, imagem, tempos e espaços de representação atuais a influência de cada um desses veículos - ou tecnologias...

Pensando nisso - na existência de um tempo anterior à influência dessas tecnologias na cultura e, portanto, nos padrões de cognição - a proposta da contextualização a seguir tem como objetivo identificar algumas possíveis vertentes históricas_ - possivelmente cognitivas - do pensamento hipertextual, compreender seus fundamentos e, por que não, identificar caminhos que poderiam ter sido seguidos para o seu desenvolvimento e que, por lógica ou acaso, não foram... ainda...

Também deve contribuir para pensar que a associação entre tecnologia e cognição não é exatamente uma novidade teórica elaborada pelos pesquisadores da era digital. 


\section{Redirecionar esforços de guerra da ciência para o cotidiano}

Contextualizar o surgimento das estruturas hipertextuais pode levar o leitor a um tempo onde não existiam computadores pessoais, muito menos Internet ... Era o tempo do fim da Segunda Guerra Mundial e os novos governantes do mundo tentavam convencer seus cientistas a redirecionarem o esforço e a criatividade que tinham desenvolvido naquela dramática direção...

Em 1945, o diretor do Escritório de Pesquisa e Desenvolvimento Científico dos Estados Unidos, Vannevar Bush, escreveu um artigo, cujo título era As we may think (Bush, 2001), o qual apresentou aos seus pares durante uma conferência que ficou famosa por antecipar concepções hoje bastante viáveis. Bush, que era matemático e físico, descreveu a idéia de reproduzir, através de um processo tecnológico de indexação e consulta, os processos mentais humanos de associação de idéias e da formação do conhecimento, através de uma rede de evocações e ligações entre os assuntos. Naquele momento, refletiu de forma antecipatória sobre as formas de arquivamento das informações, propondo que se criasse um processo inspirado na inteligência humana, que não produz uma única associação a uma idéia, como um verbete, mas que fosse capaz de criar uma rede de possíveis trilhas de idéias sugeridas pela evocação de um assunto, da mesma maneira que os humanos pensam, conectando símbolos, produzindo significados e sentidos múltiplos.

$\mathrm{Na}$ história dos hipertextos, Bush é considerado o pioneiro, o visionário que -ressalte-se novamente, em 1945! - mirou no futuro com simplicidade e escreveu seu artigo visando incentivar os cientistas da época a repassar o conhecimento desenvolvido durante a guerra ao estilo de vida das pessoas (o que, focado em perspectiva, realmente ocorreu).Ele não se esquivava de admitir-se profeta, mas alertava que: "Profecias baseadas na extensão do conhecimento têm consistência, enquanto profecias baseadas no desconhecido são apenas um desejo envolto por dubiedades".

Vejamos o que pensava Vannevar Bush e suas possíveis relações desse seu pensamento com o estudo da interatividade contemporânea e dos principais instrumentos desta, os hipertextos, para produtores e usuários de informações. Talvez se possa pensar também por que poderíamos considerá-lo uma espécie de avô dos hipertextos

\section{A mente como inspiração para documentar o conhecimento}

$\mathrm{O}$ artigo de Bush inicia com a instigante imagem, idealizada por ele, de um pesquisador em seu laboratório, com equipamentos de filmagem e gravação de som acoplados a seu corpo (mãos livres, movimentação desimpedida), os quais podem ser permanentemente acionados, enquanto o cientista vai descrevendo o que vê e o que faz, ao mesmo tempo em que tem acesso e pode retornar a qualquer momento sobre suas anotações anteriores. Essa espécie de documentação em múltiplos formatos concomitante ao trabalho do cientista seria fonte de geração e disseminação de conhecimento, além de - como se sabe hoje - abastecer o necessário banco de dados dinâmico que viabiliza - e organiza - qualquer pesquisa. $\mathrm{O}$ cientista proposto por Vannevar Bush teria um papel menos burocrático e mais desafiador. 
$\mathrm{Na}$ atividade do cientista, diz Bush, existem ações criativas e ações mecânicas. Essas últimas, repetitivas por natureza, podem e devem ser feitas pelas máquinas,

que deverão facilitar as ações humanas. Caberá à máquina, por exemplo, programada a partir de cartões perfurados (os primeiros formatos da programação dos computadores), inserir figuras e colunas, combinando células fotoelétricas e circuitos elétricos, escreve Bush. Essas mesmas máquinas serão capazes de processar dados e cálculos fantásticos, num salto de qualidade semelhante ao que ocorreu desde o ábaco até a calculadora elétrica. Com isso, os matemáticos terão (e realmente tiveram) seus cérebros liberados do exercício penoso dos cálculos, podendo dedicá-los ao uso da lógica simbólica de alto nível, que será passível de ser aplicada aos assuntos do cotidiano.

Para lidar com a quantidade de informações que já se avolumava e deveria aumentar com essa documentação científica, Bush pensava que devia ser substituído o sistema de indexações de informações e publicações por números ou ordem alfabética. Ele justificava:

“A mente humana não funciona dessa maneira. Opera por associação. Com um item ao seu alcance, acessa intensamente ao próximo que é sugerido pela associação de pensamentos, de acordo com alguma intrincada rede de pistas deixadas pelas células do cérebro. Tem outra característica, com certeza: as pistas que não são frequentemente seguidas têm propensão para perder importância, os itens não são completamente permanentes, a memória é transitória” (Vannevar Bush, 1945).

Em lugar da indexação convencional, propunha uma indexação mecanizada, para acesso instantâneo e preciso. Através de um mecanismo que chamou Memex, composto de uma mesa com telas onde seriam projetadas informações, acionadas à distância, através de um teclado com conjuntos de botões e alavancas, propunha a integração de livros, jornais, imagens, publicações acadêmicas, correspondência de negócios e documentos manuscritos. Eles seriam expostos em uma lâmina e fotografados (com fotografias a seco, outra de suas antecipações realizada tecnologicamente hoje pelas câmeras digitais).

A semelhança do que imaginava Bush com o que são, hoje, as telas que disponibilizam documentos digitalizados, fica ainda mais evidente quando em seu artigo especifica botões para movimentar o que seriam as páginas dos livros dispostos eletronicamente, de forma rápida ou lenta, podendo inclusive levar o leitor de volta ao início do trabalho. E - para alegria dos pesquisadores contemporâneos da interatividade -, propunha que seu mecanismo permitisse ao leitor acrescentar notas manuscritas e comentários ao texto (esta possibilidade, hoje, através das ferramentas de Internet, ressalte-se, é saudada como um importante estímulo à atitude de aprendizagem cooperativa e colaborativa).

A indexação de todo o material, segundo Bush previu há mais de 50 anos, deveria ser feita através da ligação de um item a outro, pela associação de idéias, à semelhança dos links que unem conteúdos nos hipertextos informatizados atuais. O usuário iria construindo suas próprias trilhas, identificando-as por nomes específicos no seu código de livros, através do teclado. Esses nomes seriam expostos, juntamente com os nomes dos outros itens relacionados (exatamente como se programa um link, atualmente, identificando os nomes dos arquivos de 
destino e retorno). Um conjunto de itens inter-relacionados deveria gerar um novo produto, acrescido dos enfoques pessoais do usuário que produziu aquelas relações específicas, a sua própria trilha entre os itens, juntamente com as anotações manuscritas que foram sendo ao conjunto (processo semelhante ao compartilhamento e atualização de informações por múltiplos usuários em um ambiente atual de Forum, por exemplo).

Ao final, o resultado deveria assemelhar-se a um labirinto de materiais disponíveis ao usuário e a outros (uma excelente metáfora para a Internet). Bush previa que esse mecanismo iria viabilizar o aparecimento de novas formas de enciclopédias (o que de fato ocorreu com antes mesmo do surgimento da internet, com CDs hipertextuais de enciclopédias, dicionários e outros documentos desse tipo) e de produtos úteis para várias categorias de profissionais. Advogados teriam acesso a informações importantes para os clientes. Médicos procurariam casos similares àqueles que lhes aparecem de forma intrigantes. Historiadores teriam acesso aos aspectos importantes da cronologia.

$\mathrm{E}$, finalmente, haveria uma nova profissão, o de pesquisador nas trilhas úteis entre a enorme construção de informações (o que provavelmente deverá ainda ser tema de boas disputas entre os informatas e os bibliotecários contemporâneos...).

O visionário Vannevar Bush talvez não tivesse consciência da pertinência de suas idéias para dialogar com uma geração de internautas que desabrochou quase meio século após tê-las expressado. Apenas usou do olhar científico para juntar as pontas da tecnologia insipiente - os primeiros computadores - com a observação lógica do que deveria fazer sentido em termos de conforto para pesquisadores e apoio à recuperação de informações disponibilizadas segundo parâmetros de funcionamento associativos e evocativos da mente humana. Foi profético, como disse, mas com uma boa base de conhecimento e de lógica de raciocínio para fazer previsões.

\section{O termo hipertexto e uma visão crítica do modelo da Internet}

Cerca de duas décadas mais tarde, outro norte-americano igualmente visionário iria cunhar o termo hipertexto, dedicado à época a designar uma estrutura que deveria suportar um sistema de gerenciamento de informações textuais interconectadas em rede, representando, segundo seu criador, Theodor (Ted) Nelson, de forma clara e correta, o mundo das idéias e suas conexões. $\mathrm{O}$ projeto chamou-se Xanadu, foi duramente criticado à época de seu desenvolvimento e não influiu diretamente no chamado mainstream do desenvolvimento da engenharia de softwares, segundo seu criador, por ter sido mal-compreendido, e/ou, talvez, por falta de um bom relações públicas, também segundo Nelson (2001-A).

Ted Nelson - nascido em 1937 e ainda hoje liderando um grupo de pesquisa e desenvolvimento das idéias do Xanadu (hoje traduzidas em um modelo de software chamado ZigZag), na Universidade de Keio, em Fujisawa, Japão - não inventou apenas a palavra hipertexto. Inventou muitas outras expressões, como transclusão, estrutura xanalógica e outras, algumas das quais serão apresentadas adiante. Foi ele ainda que em 1966, falou de outra de suas visões antecipatórias, o computador portátil (uma espécie de malinha com teclado, acoplada a um monitor parecido com as mini-tevês atuais, agregado a um microfone direcional, mostrado na figura 1$)$. 


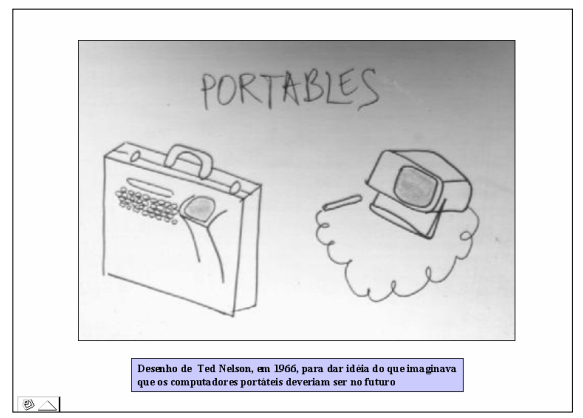

\section{Figura 1: Visão antecipatória}

de Ted Nelson sobre a

Para que não se pense que as idéias ficaram no papel, é bom lembrar que em 1973 (ou 74, dúvida manifestada pelo próprio Nelson, muito pouco preocupado em formalizar ou tornar acadêmicas suas apresentações $)^{4}$ - ele desenhou e Tom Barnard construiu um protótipo do "wearable" (um computador usável), que se assemelha a uma grande mochila e um capacete com dois projetores acima da testa, e duas telas à frente dos olhos, com uma câmera acoplada por sobre a cabeça do usuário (o irmão de Nelson, Daniel). O nome do novo produto: Porta-Xan (figura 2)

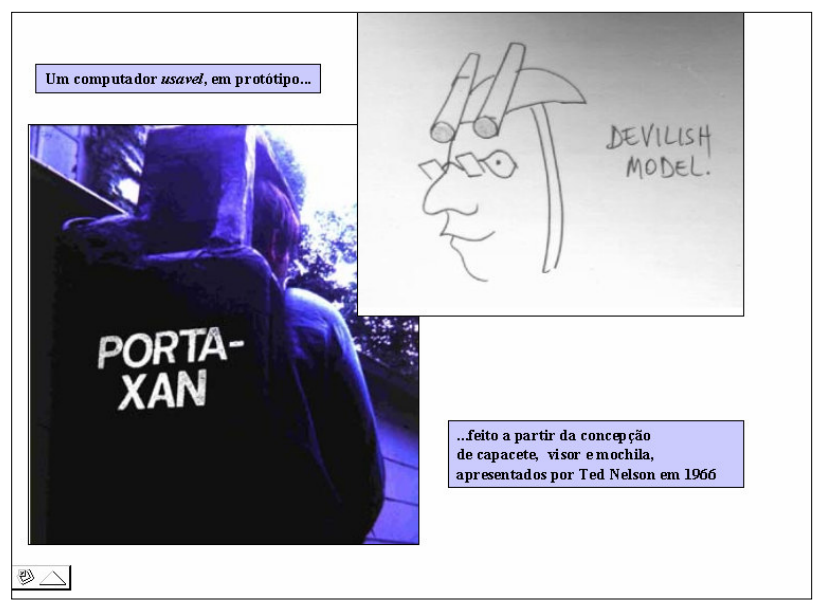

Figura 2 - Protótipo de um computador usável, como uma mochila, concebido por

Essa rápida apresentação de Ted Nelson dá uma idéia de que, a julgar pelos seus textos e sua história, além de visionário Nelson acrescentou uma fantástica dose de criatividade e inventividade às suas próprias habilidades de programador e analista. Uma história que talvez não tenha contribuído para posicioná-lo na indústria contemporânea, mas que constitui inesgotável fonte de elementos de estudos para os pesquisadores da interatividade e dos seus usos.

O hipertexto proposto por Nelson no modelo Xanadu, foi, segundo ele mesmo (Nelson, 2001-B), "mal-compreendido como uma tentativa de criar a World Wide Web". O que ele pretendia era criar um sistema direcionado a documentar todas as versões de documentos escritos (expansível a outras mídias),

\footnotetext{
${ }^{4}$ Ver Nelson (2001-A)
} 
com as alterações (correções, inclusões ou eliminações de partes) identificadas em cada uma delas, com as respectivas indicações (links) bi-direcionadas (o que foi alterado e de onde foi alterado, com sistema de ida e volta). Útil para apoiar o trabalho acadêmico, editorial, com legislação, de diplomacia e para todas as outras atividades que envolvessem documentos inter-relacionados, esta estrutura xanalógica, segundo Nelson, deveria permitir um método integrado de gerenciamento de múltiplas versões dos documentos, através de comparação direta, lado-a-lado, de suas partes, o que deveria ser um valioso suporte para a cobrança de direitos autorais especificamente relacionados àquela parte copiada (a transclusão).

Ted Nelson ainda considera que o Xanadu é um paradigma alternativo ao universo computacional que se estabeleceu depois dele, com a peculiaridade de ter durado 40 anos (foi iniciado em 1960!) como idéia que ainda encontra apoiadores e gera sub-produtos, direta ou indiretamente. Seu projeto era não apenas substituir a mídia papel, mas a própria estrutura de organização dos computadores, em hierarquia de arquivos, os quais são vistos por Nelson como enormes blocos de informação, com nomes pomposos, em lugares fixos. Em lugar dos arquivos, ele propunha uma estrutura baseada em listas de conteúdos, com interpenetrabilidade, alta taxa de conectividade, uma trilha de retorno sobre a busca racionalizada e, sobretudo, um trabalho mais criativo e similar ao pensamento humano.

A idéia do Xanadu era trabalhar com textos paralelos (outra expressão cunhada por Nelson, significando versões diferentes do mesmo texto), disponibilizadas na mesma tela, em janelas de transpointing (preparadas para essa disponibilização comparada), nas quais os conteúdos são divididos em parágrafos (as listas de conteúdos - localizáveis com o auxílio de uma relação comum - as quais designam conjuntos de caracteres ou outros elementos). Os parágrafos, por sua vez, são identificados com a mesma cor, nos dois textos, enquanto linhas interconectam, em cada um, os itens transcluídos de um para outro. O resultado visual (figura 3) é uma tela com porções coloridas ligadas por conexões bem aparentes, que mostram de onde vieram os parágrafos, o que está faltando e o que foi mudado, ou ainda indicando relações de sentido entre os conteúdos (cada tipo de link tem um tipo visual de barra de ligação).

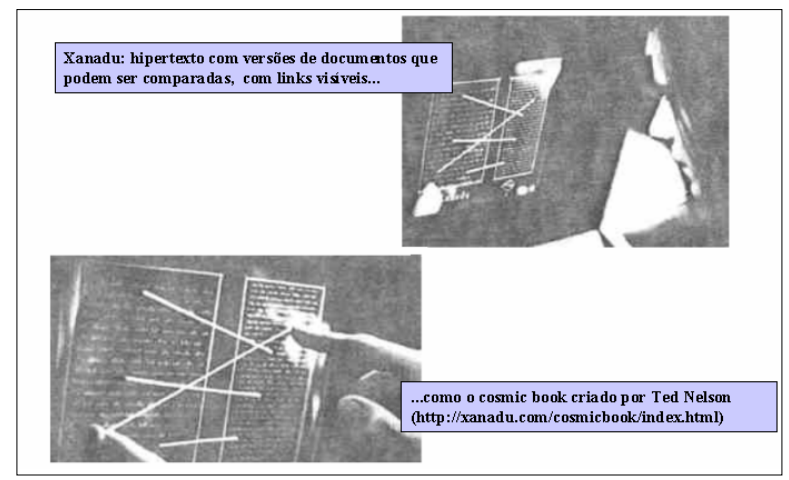

Figura 3 - Duas janelas na tela, com indicações visíveis da relação entre os parágrafos e indicações do que foi alterado em versões diferentes do

A diferença da conexão entre conteúdos proposta pelo Xanadu e a concepção dos links atuais é que a fonte da união entre os dois pontos também é identificável na tela, com a vantagem de que, se o texto for alterado, o sistema procura os caracteres remanescentes e mostra o novo link aos caracteres na nova posição. Assim, não se perdem as ligações, caso a versão do texto tenha sido alterada. Nelson baseou-se e ampliou a idéia da edição de pedaços de filmes, que 
resultam em um conjunto diferenciado. No seu sistema, qualquer pessoa, de qualquer lugar, poderá sobrepor links, comentários, etc., ao conteúdo inicial, sendo gerada uma lista de versões do documento inicial. Isso inclui até mesmo as notas pessoais inseridas marginalmente ao texto e, no caso de vídeos, a inclusão de cenas da preferência individual.

Ted Nelson considera que o paradigma de hipertextos que propôs na década de 60 não é um precursor da Internet. Bem ao contrário, a rede, como ela existe hoje, é aquilo que ele estaria tentando evitar. Em suas palavras:

"A Web deslocou o nosso modelo com alguma coisa muitas vezes mais bruta, caótica e de pouca visão. Seus links de um só sentido, que podem ser quebrados, glorificaram e fetichizaram como 'websites' aqueles diretórios bem hierarquizados, dos quais nós procuramos por usuários soltos e descartamos as idéias de uma edição estável, anotações, conexão de duas vias e trilhas acompanháveis.” (Nelson, 2001)

Como é impossível concordar ou discordar das opiniões de Ted Nelson, talvez seja oportuno observar como elas progrediram, em direção ao trabalho que realizou nos últimos anos, com pesquisadores de várias partes do mundo. O relato foi feito em 1998, em uma conferência sobre computadores usáveis, dando conta do software Zig Zag e do que chamou espaço multimensional, e identificou como "a fronteira final da mente" (Nelson, 2004). Vale lembrar que se o desenvolvimento da rede de computadores tivesse seguido pelo caminho proposto por aquele que, de fato, é o inventor dos hipertextos, talvez suas idéias fossem o eco-sistema virtual preponderante nos computadores contemporâneos e não os já conhecidos e disseminados modelos de web-sites, janelas e browsers (navegadores).

\section{6 - Multimensionalidade como espaço de representação da realidade}

Apesar de que o termo hipertexto tenha sido cunhado por Nelson na década de 60, seu uso disseminado - pelo menos no Brasil - começou a ocorrer no final da década de 90 do ano 2000, tempo em que a Internet também se popularizou e passou a fazer sentido prático, na vida dos internautas, a idéia de navegação entre conteúdos de várias naturezas linkados (o termo em inglês virou verbo de uso corrente nas rotinas de produção de material para o mundo virtual). Com o início de seu uso, disseminava-se igualmente a idéia de rede de conexões, dinâmicas, infinitas e em permanente processo de construção. Aos poucos, foram sendo elaboradas considerações sobre a natureza espacial das informações estruturadas em formatos hipertextuais, isto é, as conexões já não cabiam mais nas duas dimensões da página escrita, mas, por sua natureza hierárquica, demandavam uma organização em profundidade ou, no limite, em multidimensionalidade. Trata-se de uma idéia de difícil descrição, que tem como bom exemplo o fato de que os softwares de edição de vídeos já permitem fazer links dentro de cenas, e outros links dentro de links (Bove, 2002). Como metáfora, essa multidimensionalidade poderia ser associada aos cubos mágicos, brinquedos infanto-juvenis que permitiam a rotação de cada fatia de cada face de um cubo, tentando fazer coincidir cores que por sua vez variavam em cada fatia de face. Na metáfora, cada 
cor poderia ser um elemento do hipertexto, cuja relação com a fatia, com a face e com o cubo seria variável, segundo o movimento do navegador.

Ted Nelson perseguiu, na prática, a multidimensionalidade. O sistema que desenvolveu, o Zig Zag (Nelson, 2003), não tem, segundo Nelson, sequer uma forma definida ou uma estrutura imposta, fazendo interagir de forma múltipla um conjunto de linhas e colunas cujos elementos carregam consigo as informações e permitem conexões diferentes, para diferentes circunstâncias. Planejado para interrelacionar uma vasta quantidade de informações textuais (uma agenda, por exemplo) em unidades que são chamadas "zipper lists", o sistema permite que cada um dos itens seja integrado a essas listas já inter-relacionado lateralmente (para todos os lados, para cima, para baixo, para frente e para trás) com outros itens. A visualização das possibilidades de acesso a essas múltiplas relações será feita através de duas janelas lado a lado (como no Xanadu), ambas com um sistema de coordenadas tridimensionais ofertado na tela, através do qual o usuário saberá qual dimensão do conjunto de informações está sendo mostrada e quais ainda existem disponíveis. Em tese, podem ser usados múltiplos cursores e múltiplas janelas, desde que sejam criadas novas dimensões (até o momento do relato, Nelson ainda não havia implementado essa possibilidade). Quando o cursor (na janela de menu) se move em uma das direções do sistema de coordenadas exposto, o dado arquivado com as múltiplas relações "se abre" nessa direção (na segunda janela, a de eventos, no caso da agenda), expondo todas as conexões que trouxe com ele (seriam, ainda no caso da agenda, as informações conexas relacionadas a cada um dos eventos agendados). A conexão dentro de cada célula (conjunto de dados) é independente. Por isso, as combinações possíveis de cada item, em todas as dimensão, só serão visualizadas quando o usuário "abrir" o dado e sua célula (na figura 4).

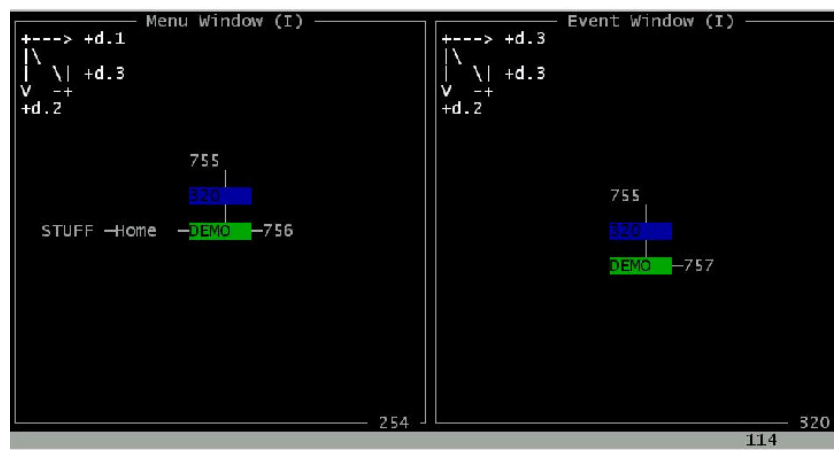

Figura 4: Interface multidimensional do software Zig Zag, de Ted Nelson (Nelson, 2004): duas janelas (uma de opções, outra dos eventos que constituem as informações, como uma agenda por exemplo), com uma indicação das três dimensões no canto superior esquerdo. As células de informação são inter-conectadas, constituindo um conjunto de conexões entre informações relacionadas por várias categorias. Em qualquer uma das dimensões (horizontal, vertical, profundidade), uma célula possui pelo menos uma célula vizinha, em cada direção.

Assim, a cada informação recuperada, o usuário traz à tela todas as combinações possíveis daquele item, algumas explícitas e outras apenas com a indicação de que existe uma conexão naquele sentido. Com essa idéia, diz Nelson, o banco de dados do sistema fica integrado a todas as demais partes do programa, inclusive a informações relevantes para cada um dos itens arquivados. 
Talvez seja uma tarefa inviável descrever com palavras uma estrutura organizacional multi-espacial e, além disso, virtual (descrições do próprio Nelson, telas e tutorial são acessíveis no endereço da Internet referido na Bibliografia), cabendo, nesse texto, apenas, a referência ao pensamento de Nelson, enquanto fonte de criação e desafios de possibilidades. Entretanto, como exercício de reflexão (temperado com um tanto de especulação), pode-se imaginar um grande hipertexto em três dimensões, operando segundo a suposta multidimensionalidade pensada por Ted Nelson, através de blocos dimensionais, sem arquivos, sem hierarquias, com listas de temas, com múltiplos cursores e janelas inter-reagentes. Pensar nessa idéia poderia remeter a um hipertexto futurista, tanto quanto a um ramo não desenvolvido da evolução das estruturas de produção e acesso a informações. Qualquer uma dessas hipóteses, por extensão, permitiria pensar nas suas possíveis diferenças em relação ao hipertexto já conhecido e consagrado pela Internet, ao qual as mentes humanas do Século XXI já se adaptaram, passaram a reconhecer (mesmo de forma inconsciente) e antecipar, através de expectativas, desejos, crenças e suposições de funcionamento.

\section{7 - Mouse e janelas: o acesso hipertextual}

Complementando as concepções, de Bush e de Nelson, que compõem a contextualização histórica, a viabilização e a reflexão sobre a presença dos hipertextos na cultura contemporânea, acrescente-se a contribuição de um outro norte-americano, Doug Engelbart, o qual, em 1968, vai influir concretamente na concepção e na realização dos hipertextos computadorizados. A concepção, porque sua preocupação centrava-se na possibilidade de aumentar as potencialidades do intelecto humano, alargando os horizontes da possibilidade mental de construção do conhecimento. A viabilização e a realização propriamente ditas dos hipertextos também foi alterada por Engelbart, porque ele criou instrumentos capazes de intermediar de forma eficiente a relação entre o homem (o produtor dos hipertextos) e a máquina (o computador, ferramenta que possibilita o gerenciamento instantâneo das ligações das informações, sejam elas em texto, som, imagem ou outras).

Os principais desses instrumentos foram o mouse, periférico que permite a escolha, na tela, de informações que serão acessadas ao toque de uma tecla, e as janelas (windows), espaços que se abrem na tela, e que correspondem à abertura de arquivos ou programas contendo informações ou ordens de gerenciamento, e que consubstanciam a multiplicidade de opções acessível ao simples ato de clicar. Através do desenvolvimento de soluções tecnológicas, Engelbart traduziu uma boa idéia em possibilidade concreta e, na prática, colocou ao alcance de qualquer criança a comunicação com um poderoso mecanismo de computação e todas as suas potencialidades de produção e acesso às representações hipertextuais do mundo.

Atualmente, os hipertextos são objetos de estudo tanto pela sua capacidade de estruturar informações na forma de redes não lineares e interativas, quanto pelas especulações a respeito das possibilidades de expansão dos processos cognitivos humanos, ao realizar as atividades de produção e mesmo de uso dos produtos em hipertexto e hipermídia. Com isso, as três visões dos precursores da idéia de certa forma se complementam: supõe-se, ainda hoje, que as estruturas podem reproduzir o processo evocativo do raciocínio (como pensava Bush); estimular a capacidade de associar, de interagir e de buscar novas possibilidades 
de enfoque sobre um tema, que chama de "interfaces" do assunto (como sonhava Ted Nelson e apesar de suas críticas); além de reproduzir metaforicamente a construção do conhecimento humano, de forma complexa (como pensava Engelbart), através de redes dinâmicas de significados.

$\mathrm{O}$ universo de complexidades que passou a girar em torno dos computadores, da Internet e de seus múltiplos usos não decorreu, evidentemente, apenas da idéia bem-sucedida da organização hipertextual de informações. Várias gerações de informatas, engenheiros e usuários da nova linguagem, em todas as áreas, deram consistência ao mundo virtual que hoje é parte da vida cotidiana, ao ponto de ter influenciado nas demais formas de expressão, como o jornal, a televisão e o cinema, tendo passado a fazer parte do processamento cognitivo da cultura do deste Século. ${ }^{5}$

É verdade inclusive que muitos ambientes virtuais facilitaram o processo de integração de arquivos de múltiplas mídias através de templates, muitas vezes engessadas na concepção de simples menus, o que de certa forma elimina a magia da criação da relação entre sentidos, às vezes ocultos no conteúdo de textos e imagens de várias naturezas, o que talvez tenha regrado um possível fascínio do link que acompanhou muitas produções experimentais, no início da implementação dos hipertextos ${ }^{6}$. Mas ainda cabe pensar sobre a importância dos hipertextos e da hipermídia para viabilizar de forma dinâmica, criativa e absolutamente não-linear de um conjunto de ações tão integrado ao projeto existencial humano: pensar-representar-criar-aprender. Em especial, na sua influência nas formas de transmissão de conhecimento e, portanto, no seu papel educacional, em especial através da Internet. O desenvolvimento tecnológico permitiu que também fossem agregados à Internet os recursos de hipermídia, como elementos de apoio aos ambientes educacionais. Essa possibilidade foi drasticamente potencializada pela popularização dos softwares que viabilizam a transmissão de áudio e imagens, estáticas ou em movimento, em tempo real ou sob demanda, através do chamado videostreaming ${ }^{7}$, que reduziu o tempo necessário para acesso a arquivos muito grandes.

\section{distância}

\section{8 - A Internet e a hipermídia redefinem a natureza do ensino a}

A Internet não alterou apenas a cultura educacional, mas também redimensionou uma forma de ensino que já era bem conhecida, o ensino a distância (EAD), cujas origens remontam aos anos 30 do Século XIX, de forma estruturada. A rigor, o ensino a distância enquanto característica de aprendizagem autônoma do estudante, se estabelece quando se imprimem os primeiros livros e, com eles, um padrão de acesso ao conhecimento independente da presença de algum professor. Mas, como formato estruturado de cursos remotos, segundo Peters (2001), surge com os registros de lições de estenografia em cartões postais, na Inglaterra, na época referida. Mais tarde, em 1856, os primeiros cursos completos foram estruturados na Alemanha, de lingüística e conversação, através de cartas que continham exercícios cujas soluções seriam dadas nas aulas

\footnotetext{
${ }^{5}$ Sobre o diálogo entre mídias convencionais e a Internet, ver Timm(2003)

${ }^{6}$ Sobre o fascínio do link, ver Timm (1998)

${ }^{7}$ Videostreaming é o processo de transmissão e decodificação simultânea, através de pacotes de informação, que não são transferidas para o computador do usuário, mas visualizadas ou ouvidas a cada acesso, a partir de um servidor de onde sejam disponibilizadas nesse formato.
} 
seguintes. Ao longo da década de 70 do Século XX, compatível com as necessidades de massificação da educação formal, foram montadas universidades a distância, em especial na Alemanha e na Inglaterra $^{8}$, que desenvolveram modelos principalmente baseados na tecnologia papel, difundida através do correio convencional. Kramer (1999) salienta a característica do ensino a distância, tendo sua implantação de forma massificada, ao longo do século XX, principalmente nas áreas ligadas aos cursos profissionalizantes. $\mathrm{O}$ mesmo vai acontecer no Brasil, quando em 1941 são criados o Instituto Universal Brasileiro e o Instituto Radiotécnico Amador, com cursos de datilografia e radiotécnica por correspondência, conhecidos através de seus anúncios divulgados em revistas, que traziam depoimentos e fotografias de alunos. ${ }^{9}$

No final dos anos 90, entretanto, os relatos de uso de ensino a distância já incorporam experiências com uso de videoconferências, primeiro através de transmissão por satélite e depois através de Internet. Ao longo desse período, começam a ser desenvolvidos ambientes virtuais de ensino-aprendizagem, cuja navegação hipertextual aos poucos foi agregando também múltiplas mídias (hipermídia), ferramentas de comunicação e compartilhamento de conteúdos previamente produzidos, estratégias de ensino-aprendizagem síncronas e assíncronas, abordagens pedagógicas especificamente desenvolvidas para a Internet e outras, adaptadas na pesquisa educacional convencional. Graças ao novo ambiente tecnológico, onde ganhou novo formato e novas possibilidades, Ensino a distância torna-se uma expressão cultuada nos níveis de planejamento da educação profissional e também no ensino acadêmico. O novo EAD contém a natureza múltipla e a potencialidade dos computadores, de interação e comunicação, além de estender a alunos e professores o universo da representação e acesso hipermediático. Como parte de um apanhado histórico sobre ensino a distância as possibilidades abertas pela popularização do uso dos computadores, Peters (2001) refere-se a características importantes dos hipertextos e da hipermídia para o ensino a distância: a facilidade de localização e acesso às informações e a existências de camadas, às quais os estudantes vão acessando, de acordo com seu desejo de aprofundamento no assunto e também como ferramentas para levar os alunos a comportamentos mais autônomos e ativos em relação ao seu próprio aprendizado, dando-se, por exemplo, a atitudes inovadoras, como o browsing (uma "folheada" aleatória pelas telas) despretensioso para estimular a

${ }^{8}$ Em ambos os países, como em outros, o modelo de ensino a distância continua sendo usado para o ensino formal e fortemente implantado como educação continuada. Há vários relatos de cursos que integram o sistema convencional, de troca de correspondência, ao uso de tecnologia informatizada e Internet.

${ }^{9}$ Nos anos 60 e 70, no Brasil, houve uma tentativa de implantação de EAD por rádio, com projetos ligados à Igreja Católica. Em 67, a Fundação Padre Anchieta, ligada ao Governo São Paulo, montou 25 postos de recepção, junto a estabelecimentos comerciais, industriais e bancários, presídios, hospitais e outras entidades religiosas e assistenciais, onde eram feitos os registros de frequiência dos alunos aos cursos. Em 80, esta Fundação passa a integrar o Sistema Nacional de TV Educativa - SINTED, do qual fazem parte oito emissoras de televisão do país, que passam a intercambiar programas educacionais com emissoras de outros países, como Portugal e até EUA. No RS, a Fundação Padre Landell de Moura (FEPLAN), desde 1967, desenvolveu várias atividades, também destinadas à profissionalização, inclusive para a população rural. Mas o que ficou mais conhecido, em todo o país, foi o chamado Telecurso de $2^{\circ} \mathrm{Grau}$, lançado pela Fundação Roberto Marinho juntamente com o Sistema Globo de Televisão em 1978, ainda existente com o nome de Telecurso 2000. O perfil dos alunos desses cursos já não estava apenas restrito aos aspirantes à profissionalização, uma vez que o ensino a distância passou a ser tratado como prioridade das instituições universitárias e mesmo do MEC, para todas as áreas da educação formal. Em setembro de 1995, foi criada no MEC a Secretaria de Educação a Distância (SEED), que passou a centralizar a formulação de políticas e projetos dessa área. Desde 1999, a Universidade de Brasília desenvolveu o projeto Universidade Virtual, oferecendo vários cursos on-line. Nesse mesmo período, foi criada a UNI-REDE, integrando universidades públicas brasileiras em projetos integrados de ensino a distância. 
curiosidade, de forma a chegar a um saber estruturado, pelo método exploratórioassociativo, que seria característico do estudo por hipertextos. Um outro tipo de browsing, igualmente possibilitado pelas novas estruturas hipertextuais, segundo ele, é a busca direcionada a um determinado objetivo, que leva os estudantes não desviar sua atenção das múltiplas possibilidades de navegação, desenvolvendo a habilidade de escolha, dentre os links, daqueles que têm mais probabilidade de levar ao objetivo desejado.

É exatamente a estrutura hipertextual, viabilizada e fermentada pelo desenvolvimento de eficientes ferramentas da informática, que viabiliza o que o professor Peters (2001) chamou de comunidade de construção de conhecimento (knowledger building community). Indicando (sem declinar a data e o local) a origem da idéia de uso compartilhado de informações em um projeto de pesquisa de um grupo de pesquisadores em microbiologia, que desejavam informar-se mutuamente sobre os resultados da pesquisa, o autor define o resultado do hipertexto conjunto como: "um arquivo central de cuja montagem todos participavam” (Peters, 2001. p. 241), uma idéia que vem sendo aperfeiçoada nos chamados ambientes educacionais virtuais, através de espaços para aprendizado colaborativo, através da produção coletiva de textos, desenhos e mesmo da resolução de problemas matemáticos.

Cabe ainda salientar a ergonomia dos hipertextos em relação ao que o mesmo autor (Peters, 2001) refere como uma das questões mais importantes do ensino a distância, ao longo de toda a sua história: a preocupação em estabelecer uma postura de diálogo com os estudantes. Por sua natureza interativa, as estruturas de informação hipertextuais são compatíveis com a oferta à participação ativa do aluno, o que pode implicar, desde seu planejamento, a conscientização, pelo professor, da postura do diálogo e da interlocução. Desde o tempo em que a comunicação se estabelecia através de correspondência convencional, a preocupação com o diálogo esteve presente na procura por estilos mais flexíveis de apresentação de conteúdos, seja através da busca da coloquialidade (conversação); da produção de textos atraentes graficamente e auto-instrutivos; seja através de tutorias de aconselhamento ou mesmo de fitas de audio e vídeo, integradas ao material impresso. O elemento "diálogo", segundo o autor, na estrutura do ensino a distância, teve importância fundamental nas experiências bem sucedidas e deveria - como de fato ocorreu - ser dramaticamente potencializado através das áudio e videoconferências. Entre outras naturezas pedagógicas, diz Peters (2001), o diálogo tele-educativo transforma a relação eucoisa em relação eu-tu, e, portanto, em uma relação sujeito-sujeito, o que é particularmente importante para minimizar a o anonimidade entre a massa de alunos e o professor distante. Em termos antropológicos e filosóficos, ressalta a importância do diálogo como ferramenta de autoconhecimento e autocertificação, citando Pöggeler e a tese: "Dialogo, logo existo" (p. 81).

As transmissões interativas (através do formato videostreaming com participação dos alunos através de chat), talvez se constituam, atualmente, em uma espécie de pré-história das potencialidades do que poderá ser, no futuro, o diálogo virtual, áudio-visual, em tempo real, de múltiplas vias (professor-aluno, alunoprofessor, aluno-aluno), do ensino a distância. Integrados através de estratégias pedagógicas flexíveis e criativas e de um planejamento capaz de integrar a potencialidade dos bancos de dados em hipermídia e da interatividade em tempo real, os futuros programas de EAD talvez possam cumprir a promessa que 
historicamente vem sendo reafirmada pelos idealizadores das novas formas de pensar, documentar e representar o mundo, hipertextualmente.

\section{Referências Bibliográficas}

BUSH, Vannevar. As we may think, disponível em http://ccat.sas.upenn.edu/ jod/texts/vannevar.bush.html, acesso em 25/10/2001. Versão eletrônica preparada por DUCHIER, Denys, April 1994 (dduchier@csi.uottawa.ca.)

BOVE, , V.M.; DAKS, J.; CHALON, E.; AGAMANOLIS, S. Hyperlinked television research at the MIT Media Laboratory, in: IBM System Journal, vol. $39, \quad n . \quad 3 \quad$ e $\quad 4, \quad 2000, \quad$ disponível em http://www.research.ibm.com/journal/sj/393/part1/bove.pdf, acesso em 19/08/2002.

HILLIS, Daniel. O padrão gravado na pedra. As idéias simples que fazem os computadores funcionarem. Rio de Janeiro: Ed. Rocco, 2000, 157 p.

LEVY, Pierre. Tecnologias da Inteligência. São Paulo: Editora 34, 1993

NELSON, T. H., What's On My Mind, disponível em www.sfc.keio.ac.jp/ ted/zigzag/xybrap.html, acesso em 29/11/01(A)

NELSON, T. H., Xanalogical Structure, Need Now More than Ever: Parallel Documents, Deep Links to Content, Deep Versioning and Deep Re-Use, disponível em www.sfc.keio.ac.jp/ ted/xuDation.html, acesso em 29/11/01(B)

NELSON, T. H., Deep Hyper Text: The xanadu. Model, disponível em www.xanadu.com/xuTheModel/, acesso em 29/01/01(C)

NELSON, T. H., The Zig Zag Software, disponível em http://www.xanadu.com/zigzag/, acesso em 29/01/2004

PETERS, Otto. Didática do ensino a distância. São Leopoldo: Editora Unisinos, 2001, 402 p.

TIMM, M.I.; SCHNAID, F; ZARO, M.A.; FERREIRA F' ${ }^{\circ}$ R.C.M.; CABRAL, P.A.F.; ROSA, A. M.; JESUS, M. Tecnologia Educacional: mídias e suas linguagens. RENOTE - Revista Novas Tecnologias na Educação, CINTED, Porto Alegre, disponível em http://www.cinted.ufrgs.br/renote/ vol 1. n. 2, Setembro/2003 II Ciclo de Palestras Novas Tecnologias na Educação

TIMM, M.I. A produção de hipertextos e a formação de possíveis cognitivos. Revista Coletâneas do Programa de Pós-Graduação em Educação, Porto Alegre, Universidade Federal do Rio Grande do Sul (PPGEDU/UFRGS), vol. 6, n. 17, 1998. 